\title{
Intramolecular Excimer Formation in a Tripodal Polyamine Receptor Containing Three Naphthalene Fluorophores
}

\author{
M. Teresa Albelda, ${ }^{\dagger}$ Enrique García-España, ${ }^{* \dagger}{ }^{\dagger}$ Laura Gil, ${ }^{\dagger}$ João C. Lima, ${ }^{\ddagger}$ Carlos Lodeiro, ${ }^{\ddagger}$ \\ J. Seixas de Melo, ${ }^{\S}$ M. João Melo, ${ }^{\ddagger}$ A. Jorge Parola, ${ }^{\ddagger}$ Fernando Pina, ${ }^{*}$, and Conxa Soriano \\ Departament de Química Inorgànica, Facultat de Química, Universitat de València, Burjassot, Spain, \\ Departamento de Química, REQUIMTE/CQFB, Faculdade de Ciências e Tecnologia, Universidade Nova de \\ Lisboa, Portugal, Departamento de Química (CQC), Faculdade de Ciências e Tecnologia, Universidade de \\ Coimbra, Portugal, and Department de Química Orgánica, Facultat de Farmacia, Universitat de València, \\ Burjassot, Spain
}

Received: February 5, 2003; In Final Form: April 30, 2003

\begin{abstract}
A comprehensive investigation on the energetics and dynamics of a new fluorescent sensor constituted by a tripodal polyamine receptor containing three naphthalene fluorophores, compound $\mathbf{L}$, is reported. The influence of external factors such as the solvent, hydrogen ion concentration, and temperature in the photophysics of the sensor is discussed. The temperature dependence of monomer/excimer interconversion of $\mathbf{L}$ revealed an average percentage relative sensitivity of $4.5 \% /{ }^{\circ} \mathrm{C}$ thus portending its use as a temperature sensor. The activation energy for excimer formation $\left(E_{1}=12 \mathrm{~kJ} \mathrm{~mol}^{-1}\right)$ and dissociation $\left(E_{-1}=57 \mathrm{~kJ} \mathrm{~mol}^{-1}\right)$, entropy change $(\Delta S$ $\left.=-128 \mathrm{~J} \mathrm{~K}^{-1} \mathrm{~mol}^{-1}\right)$, and the binding energy of the excimer $\left(\Delta H=45 \mathrm{~kJ} \mathrm{~mol}^{-1}\right)$ were obtained in water at acidic $\mathrm{pH}$ values and ethanol $\left(E_{1}=15 \mathrm{~kJ} \mathrm{~mol}^{-1}, E_{-1}=40 \mathrm{~kJ} \mathrm{~mol}^{-1}, \Delta S=-61 \mathrm{~J} \mathrm{~K}^{-1} \mathrm{~mol}^{-1}\right.$, and $\Delta H=$ $25 \mathrm{~kJ} \mathrm{~mol}^{-1}$ ). The dependence of the kinetic and thermodynamic parameters on the dielectric constant of the medium and on the degree of protonation of the polyamine chain was interpreted in terms of the excimer destabilization provoked by the electrostatic repulsion between the positively charged chains.
\end{abstract}

\section{Introduction}

Compounds displaying monomer-to-excimer interconversion can offer a diversity of applications as sensor units, in particular as fluorescent temperature sensors, because both the associative $\left(k_{1}\right)$ as well as the dissociative $\left(k_{-1}\right)$ rate constants are temperature dependent. ${ }^{1,2}$ The paradigmatic example of excimer formation is pyrene, which has been used to study conformational changes in polymers, polymer surfactant interactions, aggregation number of surfactant(s), micelle formation, etc., ${ }^{3,4}$ and was also found to have potential usefulness as a temperature sensor. ${ }^{5}$

Inter and intramolecular monomer/excimer kinetics temperature dependence is a well-known and well studied phenomenon. ${ }^{6,7}$ The Arrhenius plots of the logarithm of the excimer-to-monomer fluorescence intensity as a function of the reciprocal of temperature, known as Stevens-Ban plots, ${ }^{6}$ are commonly used to obtain the activation energy of the monomer-to-excimer barrier and/or the binding energy of the formed excimer. There are obviously other characteristics that should be taken into account in order to fully equate the advantages of such a fluorescent-based temperature sensor: monomer-to-excimer formation should be intramolecular, excimer emission should be present in a wide spread range of temperatures, and the photostability of the sensor must

* To whom correspondence should be addressed. (E.G.-E.) Fax: 963864322. Phone: 963864879. E-mail: enrique.garcia-es@uv.es. (F.P.) Fax: 212948550. Phone: 212948355. E-mail: fjp@dq.fct.unl.pt.

† Departament de Química Inorgànica, Facultat de Química, Universitat de València.

$\doteqdot$ Universidade Nova de Lisboa.

$\S$ Universidade de Coimbra.

"Department de Química Orgánica, Facultat de Farmacia, Universitat de València.

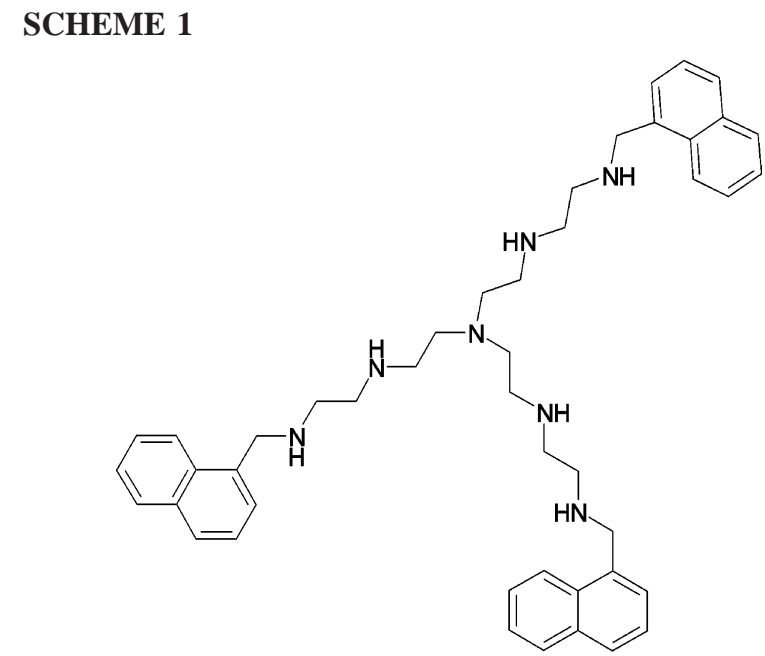

$\mathbf{L}$

also be considered (Scheme 1). In previous work we have described the intramolecular monomer/excimer interconversion of systems consisting of a polyamine chain, end-terminated by two naphthyl units. ${ }^{8-10}$ The introduction of polyamine chains in the compounds is interesting from several points of view. First, it increases the relative water solubility of the receptors above that of those containing other type of bridges such as polyethereal or conjugated polyene chains. Second, it permits the sensor to switch ON/OFF by changing the $\mathrm{pH}$, because at sufficiently high $\mathrm{pH}$ values the lone pairs of the amines are capable of quenching the fluorescence emission. ${ }^{11}$ In addition, naphthalene was introduced as a fluorophore instead of pyrene 
to allow for a high enough water solubility of the compounds to carry out the measurements in this solvent.

In this work, we report on the synthesis and photophysical properties of compound $\mathbf{L}$, which bears three naphthyl groups attached to long polyamine chains. The molecular organization of $\mathbf{L}$ can enhance the possibility for the naphthalene rings to encounter each other and provides a large excimer to monomer emission ratio. This would be analogous to intermolecular excimer formation, which is known to be favored with the increase of the monomer ground-state concentration.

Here, we present a detailed study of the excited-state kinetics of $\mathbf{L}$ in water and ethanol as well as of its temperature and $\mathrm{pH}$ dependence. The use of compound $\mathbf{L}$ as a temperature sensor based on the monomer/excimer interconversion is also discussed.

\section{Experimental Section}

Synthesis. Tosylated tren $\left(N^{1}, N^{1}\right.$-di(2-amino-ethyl)ethane-1,2diamine) was reacted with $N$-(3-bromopropyl)phthalimide to obtain the enlarged polyamine which was treated with phenol and $\mathrm{HBr}$-acetic acid solution to give the detosylated polyamine $N^{1}$-(2-\{bis-[2-(3-amino-propylamino)-ethyl]-amino\}-ethyl)-propane-1,3-diamine. This compound $(0.87 \mathrm{~g}, 2.74 \mathrm{mmol})$ and naphthalene-1-carbaldehyde $(1.60 \mathrm{~g}, 8.22 \mathrm{mmol})$ were stirred for $2 \mathrm{~h}$ in $75 \mathrm{~mL}$ of EtOH. Sodium borohydride $(0.22 \mathrm{~g}, 6 \mathrm{mmol})$ was then added and the resulting solution stirred for $1 \mathrm{~h}$. The ethanol was removed at reduced pressure. The resulting residue was treated with water and repeatedly extracted with dichloromethane $(3 \times 30 \mathrm{~mL})$. The organic phase was dried with anhydrous sodium sulfate and the solvent evaporated to yield the free amine, which was dissolved in ethanol and precipitated as its hydrobromide salt (yield 9\%). Anal. Calcd for $\mathrm{C}_{48} \mathrm{H}_{70} \mathrm{~N}_{7^{-}}$ $\mathrm{Br}_{7}: \mathrm{C}, 47.12 \% ; \mathrm{N}, 8.01 \% ; \mathrm{H}, 5.68 \%$. Found $\mathrm{C}, 46.9 \% ; \mathrm{N}$, 8.0\%; H, 5.6\%. $\mathrm{mp} 217-220{ }^{\circ} \mathrm{C} .{ }^{1} \mathrm{H} \delta_{\mathrm{H}}(\mathrm{ppm}): 2.06-2.10(\mathrm{~m}$, $6 \mathrm{H}), 2.78-3.03(\mathrm{~m}, 6 \mathrm{H}), 3.09-3.13(\mathrm{~m}, 18 \mathrm{H}), 4.63(\mathrm{~s}, 6 \mathrm{H})$, $7.43-7.55(\mathrm{~m}, 12 \mathrm{H}), 7.87-7.97(\mathrm{~m}, 9 \mathrm{H}) .{ }^{13} \mathrm{C} \delta_{\mathrm{C}}(\mathrm{ppm})=22.8$, 44.6, 44.9, 45.1, 48.2, 49.1, 122.7, 125.8, 126.4, 126.9, 127.7, 129.4, 129.7, 130.8, 131.0, 133.8 .

Potentiometry. Potentiometric measurements were carried out in $0.15 \mathrm{~mol} \mathrm{dm}^{-3} \mathrm{NaCl}$ at $298.1 \pm 0.1 \mathrm{~K}$. The program HYPERQUAD $^{12}$ was used to derive the values of the protonation constants. Stepwise constants calculated for $\mathbf{L}$ are $\log$ $K_{\mathrm{HL} / \mathrm{H} \cdot \mathrm{L}}=9.08(6), \log K_{\mathrm{H} 2 \mathrm{~L} / \mathrm{HL} \cdot \mathrm{H}}=8.72(5), \log K_{\mathrm{H} 3 \mathrm{~L} / \mathrm{H} 2 \mathrm{~L} \cdot \mathrm{H}}=$ $8.46(5), \log K_{\mathrm{H} 4 \mathrm{~L} / \mathrm{H} 3 \mathrm{~L} \cdot \mathrm{H}}=7.75(4), \log K_{\mathrm{H} 5 \mathrm{~L} / \mathrm{H} 4 \mathrm{~L} \cdot \mathrm{H}}=7.09(5), \log$ $K_{\mathrm{H} 6 \mathrm{~L} / \mathrm{H} 5 \mathrm{~L} \cdot \mathrm{H}}=6.89(4)$, and $\log K_{\mathrm{H} 7 \mathrm{~L} / \mathrm{H} 6 \mathrm{~L} \cdot \mathrm{H}}=2.3(1)$.

Photophysical Studies. All aqueous solutions were prepared in $0.15 \mathrm{~mol} \mathrm{dm}{ }^{-3} \mathrm{NaCl}$. $\mathrm{HCl}$ and $\mathrm{NaOH}$ were used to adjust the $\mathrm{pH}$ values that were measured on a Metrohm $713 \mathrm{pH}$ meter. Absorption spectra were recorded on a Perkin-Elmer Lambda 6 spectrophotometer and fluorescence emission spectra on a Horiba-Jobin Yvon-Spex Fluorolog 3.22 spectrofluorimeter equipped with a ThermoNeslab RTE7 bath. All of the fluorescence spectra were corrected for the instrumental response of the system.

The fluorescence decays were obtained using a home-built equipment that has been described elsewhere ${ }^{13}$ and were analyzed using the method of modulating functions implemented by Striker. ${ }^{14}$ All measurements were made in the presence of oxygen to reproduce the conditions of steady-state fluorescence measurements.

\section{Results}

Steady-State Fluorescence-Dependence with $\mathbf{p H}$. The fluorescence emission of compound $\mathbf{L}$, in water at $20^{\circ} \mathrm{C}$, as a function of $\mathrm{pH}$ is presented in Figure 1A. Two emisson bands
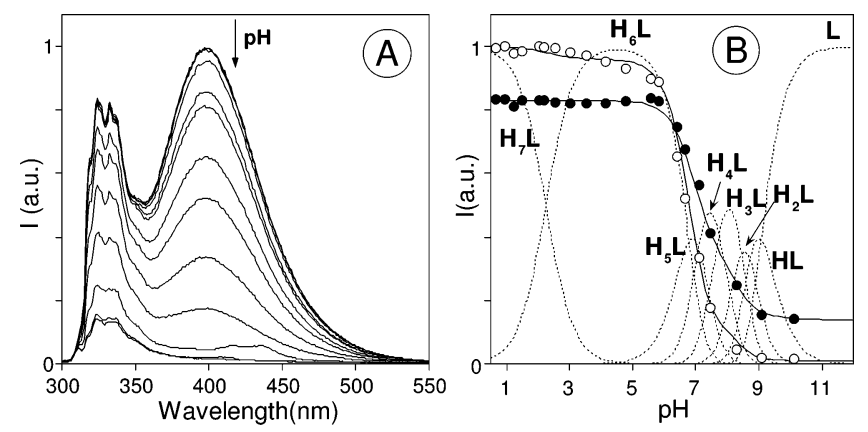

Figure 1. (A) Emission spectra of $0.15 \mathrm{~mol} \mathrm{dm}^{-3} \mathrm{NaCl}$ aqueous solutions of $\mathbf{L}$ from $\mathrm{pH}=0.8$ to 10.48 at $20^{\circ} \mathrm{C}$ and (B) variation of monomer $\left(I_{324}, \bullet\right)$ and excimer $\left(I_{399}, \bigcirc\right)$ maxima superimposed to the mole fraction distribution of species in solution obtained by potentiometry.
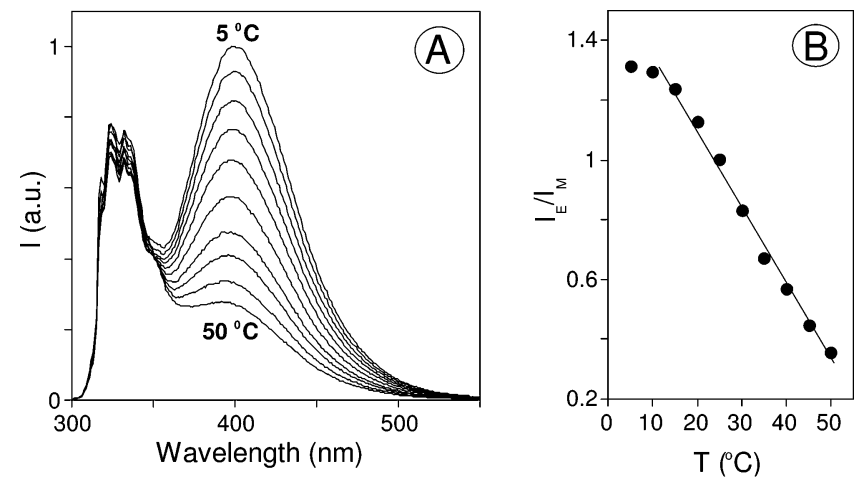

Figure 2. (A) Emission spectra of $0.15 \mathrm{M} \mathrm{NaCl}$ aqueous solutions of $\mathbf{L}$ at $\mathrm{pH}=1.0$ as a function of temperature and (B) respective $I_{399} / I_{324}$ ratio vs $T$ showing linear behavior between 15 and $50^{\circ} \mathrm{C}$.

can be observed: one with a maximum at $334 \mathrm{~nm}$ (monomer) and an additional red-shifted and nonstructured emission band, centered at $399 \mathrm{~nm}$, assigned to the characteristic excimer emission usually found in naphthalene based systems. ${ }^{8,10,15}$ Figure 1B shows the fluorescence emission titration curves, obtained by superimposing the normalized intensity at the maximum, of the monomer and excimer emissions, with the mole fraction distribution of the different species in solution (obtained by potentiometry). The emission from the two most protonated species, $\mathrm{H}_{7} \mathbf{L}^{7+}$ and $\mathrm{H}_{6} \mathbf{L}^{6+}$, has a greater contribution from excimer than from monomer. Above $\mathrm{pH}$ 6.5, where the less protonated species are present, the emission is weaker and dominated by the monomer.

Steady-State Fluorescence-Dependence with Temperature. In Figure 2A, the temperature dependence of the fluorescence emission at $\mathrm{pH}=1.0$ is presented. According to the potentiometric data in Figure $1 \mathrm{~B}$, the fully protonated form, $\mathrm{H}_{7} \mathbf{L}^{7+}$, is the predominant species at this $\mathrm{pH}$ and therefore the main contributor to the fluorescence emission. However, timeresolved fluorescence data (see below) shows that the form $\mathrm{H}_{6} \mathbf{L}^{6+}$ also contributes significantly to the emission at this $\mathrm{pH}$. The emission spectrum of $\mathbf{L}$ changes with temperature, with the total intensity decreasing with increasing temperature without showing isoemissive points (Figure 2A). This indicates that monomer and/or excimer decay compete with the monomerto-excimer direct and backward reactions and that the excitedstate equilibrium cannot be reached before emission (of both monomer and excimer). In Figure $2 \mathrm{~B}$, the ratio $I_{\mathrm{E}} / I_{\mathrm{M}}$, (excimerto-monomer ratio of the fluorescence intensity at the maxima) is plotted as a function of temperature. As temperature decreases the excimer emission is strongly favored with respect to the 

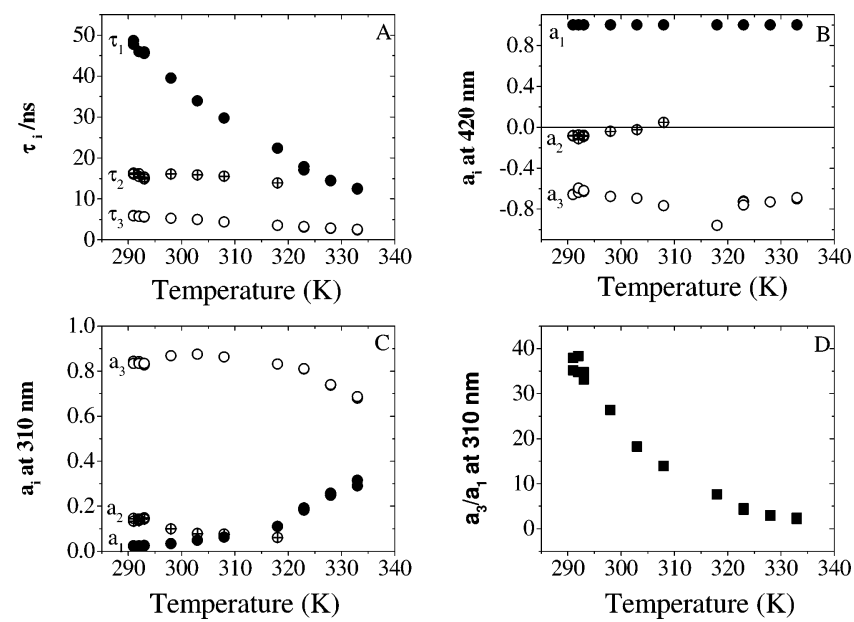

Figure 3. Temperature dependence of (A) the decay times $\left(\tau_{1}, \tau_{2}\right.$, and $\left.\tau_{3}\right)$, (B) preexponential factors $\left(a_{1}, a_{2}\right.$, and $\left.a_{3}\right)$ at $420 \mathrm{~nm},(\mathrm{C})$ at 310 $\mathrm{nm}$, and (D) of the ratio of preexponential factors of the main components $\left(a_{3} / a_{1}\right)$ at monomer emission wavelength $(310 \mathrm{~nm})$ for compound $\mathbf{L}$ in $0.15 \mathrm{~mol} \mathrm{dm}^{-3} \mathrm{NaCl}$ aqueous solution, at $\mathrm{pH}=1.7$.

monomer emission, as reflected on the ratio $\mathrm{I}_{\mathrm{E}} / \mathrm{I}_{\mathrm{M}}$, from which an average percentage relative sensitivity of $4.5 \% /{ }^{\circ} \mathrm{C}$ is obtained.

Time-Resolved Fluorescence. The fluorescence decay times of compound $\mathbf{L}$, in water, at $\mathrm{pH}=1.7$, collected at the monomer $(310 \mathrm{~nm})$ and excimer $(420 \mathrm{~nm})$ emission wavelengths were analyzed independently and by global analysis. The best fits are always multiexponential, and the temperature dependence of the decay times obtained from global analysis, as a function of temperature, is presented in Figure 3A.

At low temperatures, the decays are best fitted with sums of three exponentials, with the same decay times at both wavelengths and two negative preexponential factors at $420 \mathrm{~nm}$ (see Figure 3B). As the temperature is raised, the decays are gradually fitted with two exponentials, because the amplitude of the second decay time, $a_{2}$, at both 310 and $420 \mathrm{~nm}$, eventually goes to zero above $45^{\circ} \mathrm{C}$ (see Figure 3, parts B and C, and discussion). It can be seen that there is a large decrease of the $\tau_{1}$ value with the increase in temperature, whereas the effect of changing the temperature is less dramatic for the $\tau_{2}$ and $\tau_{3}$ values (Figure $3 \mathrm{~A}$ ). The decrease of $\tau_{1}$ is accompanied by an increase of the weight of this component in the decay at $310 \mathrm{~nm}$, as can be seen by the ratio $a_{3} / a_{1}$, Figure $3 \mathrm{D}$.

Although the sum of the preexponential factors at the excimer wavelength is never equal to zero, there is no evidence for ground-state association in this compound. ${ }^{16}$ The most probable explanation is that the contribution of monomer emission below the excimer emission band is inducing the decrease in the negative preexponential factor. In fact, increasing the emission wavelength leads to an increase in the absolute value of the negative preexponential factor. However, in the great majority of the experiments performed, the emission wavelength in the excimer region was settled at $420 \mathrm{~nm}$ (low energetic end of the excimer band) as a compromise between avoiding monomer contribution and keeping a good sensitivity for detection of the excimer emission.

When studied in hydroxylic organic solvents such as ethanol and methanol, the steady-state fluorescence spectra revealed monomer and excimer emission bands similar to those abovereported for water. In neutral methanol and in ethanol, the fluorescence decays are reduced to biexponential decays, Figure 4A. However, when acidified methanol is used $(\mathrm{HCl})$, a third component is needed to properly fit the decay, Figure 4B.
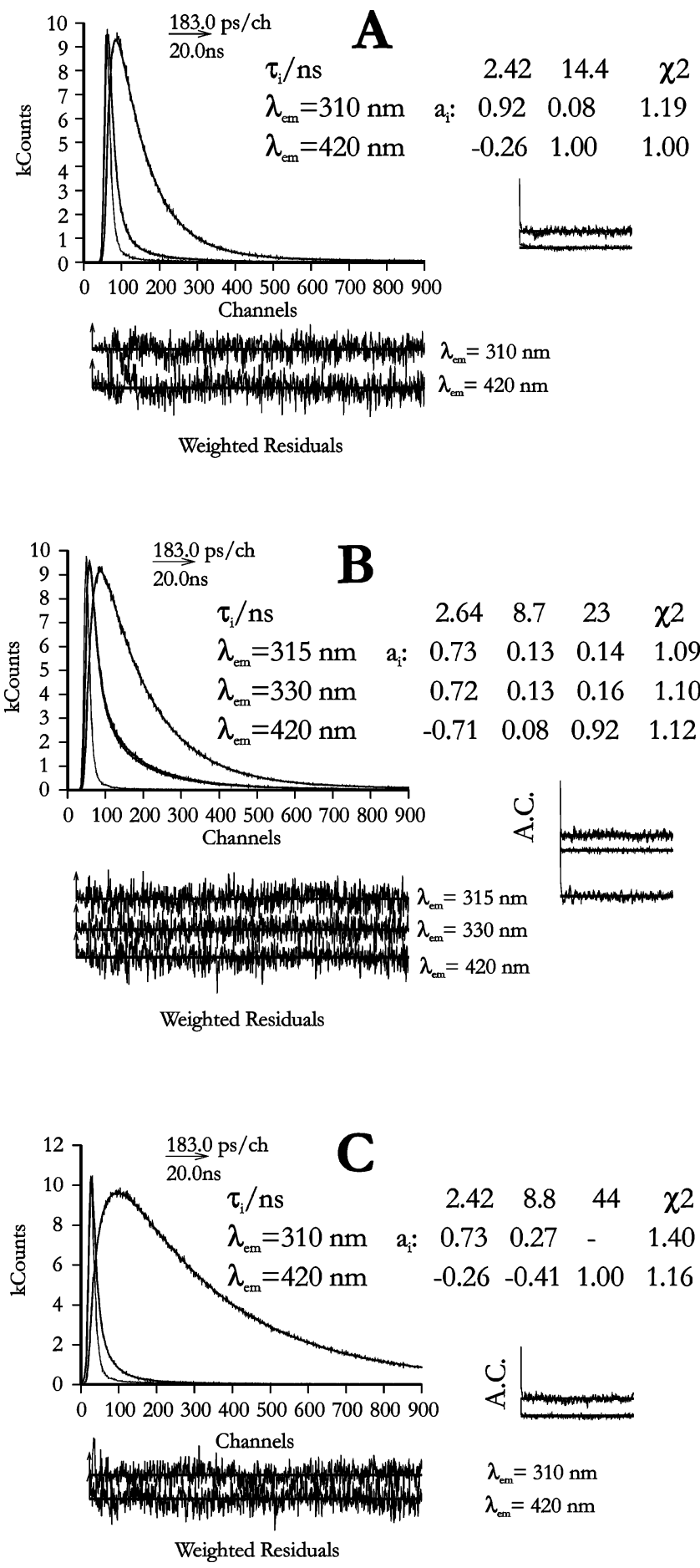

Figure 4. Fluorescence decays obtained with global analysis for compound $\mathbf{L}$ in (A) neutral methanol, (B) acidified methanol, and (C) $0.15 \mathrm{~mol} \mathrm{dm}^{-3} \mathrm{NaCl}$ aqueous solution, at $\mathrm{pH}=0.64$. The instrument profile curve is also shown. For a better judgment of the quality of the fits, shown as insets are the weighted residuals, autocorrelation (A.C.) functions, and chi-squared $\left(\chi^{2}\right)$ values.

Because in neutral methanol and ethanol the only species present is $\mathrm{H}_{6} \mathbf{L}^{6+}$, we attribute the third (intermediary) component to the species $\mathrm{H}_{7} \mathbf{L}^{7+}$ formed upon acidification of methanol. This can be further illustrated by comparison of the fluorescence decays in neutral methanol, in acidified methanol, and in water $(\mathrm{pH}=0.64)$ presented in Figure 4 . The two shorter components have basically the same value in water and acidified methanol and the intermediary component is missing in neutral methanol. Furthermore, comparison of the negative amplitudes of the 


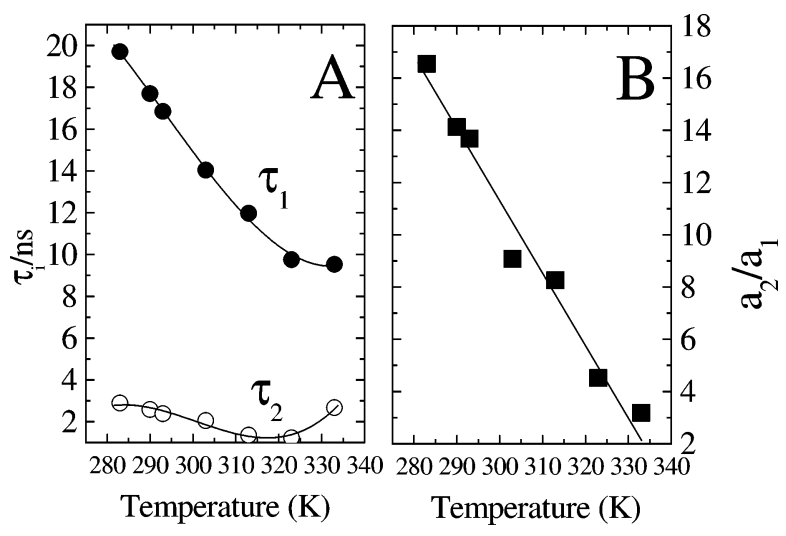

Figure 5. Temperature dependence, in ethanol, of the (A) decay times $\left(\tau_{1}\right.$ and $\left.\tau_{2}\right)$ and (B) the ratio of preexponential factors $\left(a_{2} / a_{1}\right)$ at monomer emission wavelength $(310 \mathrm{~nm})$.

decays in water, at $\mathrm{pH}=0.64\left(a_{3}=-0.26, a_{2}=-0.41\right.$; Figure $4 \mathrm{C})$ and at $\mathrm{pH}=1.7\left(a_{3}=-0.62, a_{2}=-0.09\right.$; Figure $\left.3 \mathrm{~B}\right)$ shows that the weight of the intermediary component $\left(\tau_{2}\right)$ increases with a decrease in $\mathrm{pH}$ at the excimer emission wavelength.

In neutral ethanol, when the temperature is changed, it is again possible to observe a general pattern identical to that which was found in water, except for the fact that only two decay times are present. As in water, there is a large decrease of the longer decay time, $\tau_{1}$, with the increase in temperature (Figure 5A) and a more constant behavior of the shorter decay time, $\tau_{2}$, with temperature. Also here the decrease of $\tau_{1}$ is accompanied by the increase of the weight of this component in the decay at $310 \mathrm{~nm}$, as can be seen by the ratio $a_{2} / a_{1}$, Figure $5 \mathrm{~B}$.

\section{Discussion}

Steady-State Fluorescence-Effect of the pH on Fluorescence Intensity. Observation of Figure 1B shows that the fully protonated species, $\mathrm{H}_{7} \mathbf{L}^{7+}$, together with the $\mathrm{H}_{6} \mathbf{L}^{\mathbf{6}+}$ form, exhibit the most intense emission (both monomer and excimer). The removal of a second proton, which may occur from one of the secondary nitrogens, induces a strong quenching effect due to electron transfer from the amine lone pair to the excited naphthalene. This type of quenching has analogously been observed in other polyamine systems bearing benzene, naphthalene, or anthracene fluorophores. ${ }^{9-11}$ This quenching becomes progressively dominant above $\mathrm{pH} 6.5$, leading finally to an almost complete disappearance of the emission. Therefore, although the emission dependence with $\mathrm{pH}$ limits the use of these compounds in water to the acidic region, it would on the other hand permit the system to switch ON/OFF through the action of $\mathrm{pH} .{ }^{15}$

Steady-State Fluorescence-Effect of the Temperature on Fluorescence Intensity. As predicted by the Stevens-Ban treatment, the activation energy for the excimer formation becomes the controlling step at low temperatures and as a consequence, the curve reaches a maximum and then starts to decrease. $^{6}$ In the particular case of Figure $2 \mathrm{~B}$, the lowtemperature limit of the curve cannot be observed in water. However, the slope in Figure 2B allows the calculation of an average percentage relative sensitivity of $4.5 \% /{ }^{\circ} \mathrm{C}$. This value is very reasonable when compared to the sensitivity of other fluorescent systems potentially useful as temperature sensors. It is better than the $1 \% /{ }^{\circ} \mathrm{C}$ value reported in ref 1 for a two component fluorescence temperature sensor and better than other systems based on the intensity of fluorescence, either dual-17 or single-wavelength systems. ${ }^{18-22}$ It also compares well with the sensitivity levels obtained with systems based on temperature-dependent excited-state lifetimes ${ }^{20,23,24}$ and is much better than systems based on shifts in fluorescence spectra. ${ }^{25}$ The system is not totally reversible in the temperature range tested, showing some hysteresis upon temperature cycles.

Time-Resolved Fluorescence in Water and Hydroxylic Solvents. The triexponential fitting of the decays in water (Figure 3), at both monomer and excimer emission wavelengths, with two rise-times appearing at the excimer emission wavelength, is interpreted as the sum of the contributions of the forms $\mathrm{H}_{6} \mathbf{L}^{6+}$ and $\mathrm{H}_{7} \mathbf{L}^{7+}$ that coexist in aqueous solution at those $\mathrm{pH}$ values. Excimer is formed at the expenses of the monomers of both forms with different rate constants, the most protonated form being "slower", because of the increase in activation energy provoked by the higher electrostatic repulsion in $\mathrm{H}_{7} \mathbf{L}^{7+}$. At $\mathrm{pH}$ $=1.7$, the contribution of $\mathrm{H}_{7} \mathbf{L}^{7+}$ for excimer formation is almost negligible as can be evaluated by the insignificant negative preexponential factor, $a_{2}$, associated to $\tau_{2}$ at $420 \mathrm{~nm}$, Figure 3B. In general, at the monomer emission wavelength, the longlived component, $\tau_{1}$, displays a low preexponential factor, which is an indication of a low contribution of the excimer-to-monomer reversibility process, that in this case will come almost exclusively from the dissociation of the $\mathrm{H}_{6} \mathbf{L}^{6+}$ excimer.

As the temperature is raised, the decays are gradually fitted to two exponentials. This is attained at temperatures above ca. $45^{\circ} \mathrm{C}$. The gradual change to double exponential decays is associated with the vanishing of the amplitude associated to the intermediary decay time. In our interpretation, this vanishing reflects the decrease in the ground-state concentration of $\mathrm{H}_{7} \mathbf{L}^{7+}$ because of the increase in the acidity constant with temperature. ${ }^{26}$ In fact, the ionization of weak acids such as $\mathrm{H}_{7} \mathbf{L}^{7+}$ always increases with temperature. This can be readily seen if we take into account that a weak acid always has $\Delta G^{\circ}>0 .{ }^{27}$

The small contribution of $\mathrm{H}_{7} \mathbf{L}^{7+}$ at room temperature and the decrease of this contribution with the temperature increment makes possible to treat the system as a two-state Birks ${ }^{7}$ kinetic scheme, applied to the excimer formation from $\mathrm{H}_{6} \mathbf{L}^{6+}$, in water. In fact, the decays in water should be sums of four exponentials, accounting for reversible excimer formation from both $\mathrm{H}_{6} \mathrm{~L}^{6+}$ and $\mathrm{H}_{7} \mathrm{~L}^{7+}$ species. There are however some fundamental reasons to choose a simplified treatment: (1) analysis of the decays with four exponentials did not improve the quality of the fits; (2) the intermediate component disappears above 45 ${ }^{\circ} \mathrm{C}$; and (3) even below $45{ }^{\circ} \mathrm{C}$ there is no evidence for a significant contribution from $\mathrm{H}_{7} \mathrm{~L}^{7+}$ excimer dissociation at the monomer decay, which would be reflected in a loss of linearity in the Arrhenius plots of the rate constants obtained from the simplified two state model (see Figure 6A).] For solvents such as methanol and ethanol, where $\mathrm{H}_{6} \mathbf{L}^{6+}$ is the only species present, the system behaves, in the entire temperature range, as in a classical Birks-kinetic scheme.

All of the above discussion leads to the following general kinetic scheme (Scheme 2). In this scheme, the rates of excimer formation and deactivation are given by $k_{1}$ and $k_{-1}$, respectively, $1 / \tau_{\mathrm{M}}=k_{\mathrm{M}}$ and $1 / \tau_{\mathrm{E}}=k_{\mathrm{E}}$ are the reciprocals of the unquenched lifetimes of the monomer and excimer. According to Scheme 2 , the excited-state concentration time dependence of each one of the species is given by

$$
\begin{aligned}
& {\left[M^{*}\right](t)=a_{11} \mathrm{e}^{-\lambda_{1} t}+a_{12} \mathrm{e}^{-\lambda_{2} t}} \\
& {\left[E^{*}\right](t)=a_{21} \mathrm{e}^{-\lambda_{1} t}+a_{22} \mathrm{e}^{-\lambda_{2} t}}
\end{aligned}
$$




\section{SCHEME 2}

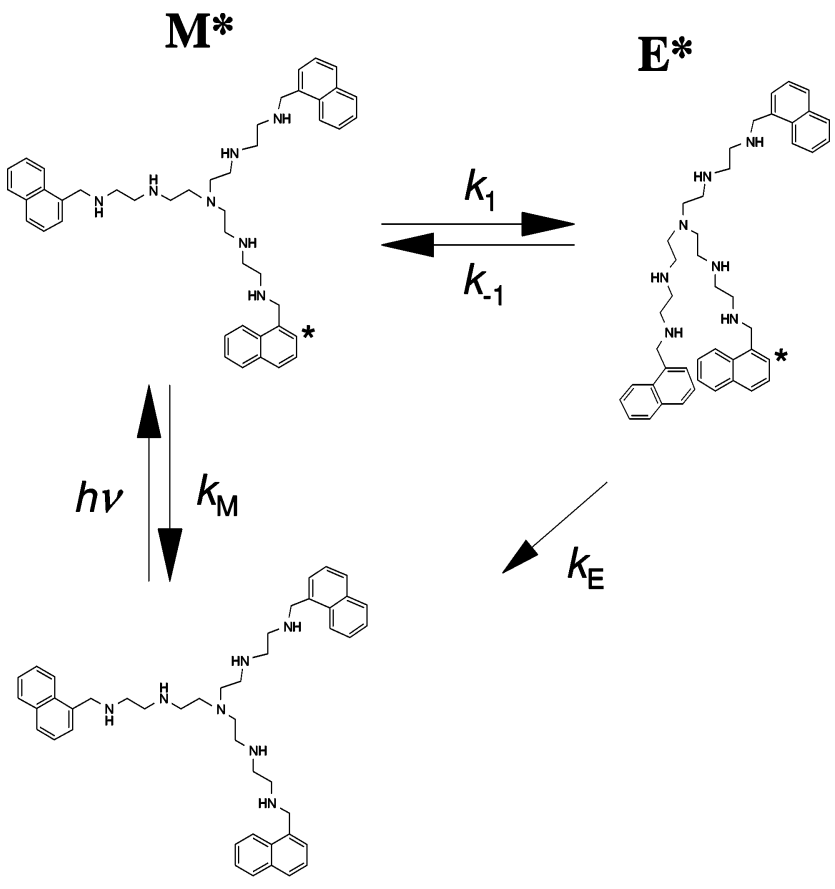

\section{$\mathbf{M}$}

The time dependence of monomer fluorescence can be described by the following equation:

$$
I_{\mathrm{M}}(t)=I_{310}(t)=a_{11} \mathrm{e}^{-\lambda_{1} t}+a_{12} \mathrm{e}^{-\lambda_{2} t}
$$

and that of the excimer emission by

$$
I_{\mathrm{E}}(t)=I_{420}(t)=a_{21} \mathrm{e}^{-\lambda_{1} t}+a_{22} \mathrm{e}^{-\lambda_{2} t}
$$

with $\lambda_{1}$ and $\lambda_{2}$ given by

$$
2 \lambda_{2,1}=\left\{\left(k_{\mathrm{X}}+k_{\mathrm{Y}}\right) \pm\left[\left(k_{\mathrm{X}}-k_{\mathrm{Y}}\right)^{2}+4 k_{1} k_{-1}\right]^{1 / 2}\right\}
$$

where $k_{\mathrm{X}}=k_{1}+1 / \tau_{\mathrm{M}}$ and $k_{\mathrm{Y}}=k_{-1}+1 / \tau_{\mathrm{E}}$.

The rate constants of excimer formation, $k_{1}$, and dissociation, $k_{-1}$ (Scheme 2), can be obtained ${ }^{7,10,15}$ from the decay times ( $\tau_{1}$ and $\tau_{3}$ in water; $\tau_{1}$ and $\tau_{2}$ in ethanol), the ratio of the preexponential factors at the monomer wavelength $\left(a_{3} / a_{1}\right.$, in water and $a_{2} / a_{1}$ in ethanol) and the lifetime of a model compound $\left(\tau_{\mathrm{M}}=1 / k_{\mathrm{M}}\right)$. The model compound used in this case was the monochromophoric compound $N^{1}-(2-\{2-[$ (naphthalen-1-ylmethyl)-amino]-ethylamino \}-ethyl)-ethane-1,2-diamine. ${ }^{10,11,15}$ This compound presents single exponential decays in water at $\mathrm{pH}=1.7$ and ethanol and was measured as a function of temperature.

Figure 6 shows the Arrhenius plots of the logarithm of $k_{1}$ and $k_{-1}$ as a function of the reciprocal temperature, both in water at $\mathrm{pH}=1.72$ and ethanol. The two rate constants follow a typical Arrhenius behavior in both solvents, and the activation energy for excimer formation and dissociation can be retrieved from the slopes of the plots (Table 1). In water, the values of

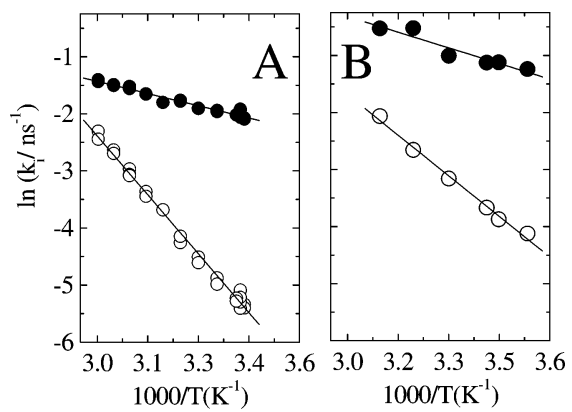

Figure 6. Rate constants for excimer formation $\left(k_{1}, \bullet\right)$ and dissociation $\left(k_{-1}, O\right)$ as a function of the reciprocal of temperature in (A) $0.15 \mathrm{~mol}$ $\mathrm{dm}^{-3} \mathrm{NaCl}$ aqueous solution, at $\mathrm{pH}=1.7$ and (B) ethanol.

$E_{1}=12 \mathrm{~kJ} \mathrm{~mol}^{-1}$ and $E_{-1}=57 \mathrm{~kJ} \mathrm{~mol}^{-1}$ yield an excimer binding energy $-\Delta H=E_{-1}-E_{1}=45 \mathrm{~kJ} \mathrm{~mol}^{-1}$, whereas in ethanol, $E_{1}=15 \mathrm{~kJ} \mathrm{~mol}^{-1}$ and $E_{-1}=40 \mathrm{~kJ} \mathrm{~mol}^{-1}$, yield an excimer binding energy of $25 \mathrm{~kJ} \mathrm{~mol}^{-1}$. Comparison of the $\Delta H$ values, obtained in water and ethanol, points out to a less stable excimer in the latter solvent. This is of straightforward interpretation on the basis of the high electrostatic repulsion felt in the lower dielectric medium ethanol.

The increase in the value of the activation energy for excimer formation $E_{1}$, from water to ethanol, is the opposite of what should be expected on the basis of solvent viscosity, indicating once more a strong contribution from electrostatic repulsion for this activation energy. Comparison of the rate constants of excimer formation in water and ethanol at $20^{\circ} \mathrm{C}$ shows on the other hand that the preexponential factor is higher in ethanol, probably reflecting a higher frequency of encounters in this solvent or a higher number of conformations where both naphthyl groups are close enough for excimer formation. The higher number of close contact conformations could also explain the much less negative entropy change for excimer formation in ethanol with respect to water, see Table 1 . In a previous work, the rate constants for excimer formation at $20{ }^{\circ} \mathrm{C}$ were measured for a series of bis(chromophoric) compounds, analogues of compound L. ${ }^{15}$ For instance, the linear bis-naphthalene compound, in which the chromophores are separated by a tetraethylenepentaamine chain, is a reasonable model for the excimer formation between two arms of compound $\mathbf{L}$. The form $\mathrm{H}_{6} \mathbf{L}^{6+}$ of compound $\mathbf{L}$ has two protons per arm, and when they approach each other, they feel the repulsion equivalent to 4 protons, as in the bis(chromophoric) analogue at $\mathrm{pH}=3.9$ where the pentaamine is tetraprotonated. Assuming that these repulsive interactions are the main contribution to the excimer formation activation energy and that they are similar in both compounds, the ratio of the rate constants of excimer formation at $20^{\circ} \mathrm{C}$ would yield roughly the ratio of the preexponential factors for excimer formation in both compounds. At $20^{\circ} \mathrm{C}$ in water, $k_{1}=$ $0.13 \mathrm{~ns}^{-1}$ for compound $\mathbf{L}$ and $0.05 \mathrm{~ns}^{-1}$ for the linear compound, ${ }^{15}$ reflecting that the additional arm in $\mathbf{L}$ roughly doubles the probability of finding a conformation where both naphthyl groups are close enough to reach contact for excimer formation.

Previous works have showed that intramolecular excimer formation with naphthalene attached to the ends of methylene chains was nearly completely limited to a trimethylene chain ${ }^{28}$

TABLE 1: Kinetic and Thermodynamic Parameters for Excimer Formation, Obtained from the Temperature Dependence of the Fluorescence Decays

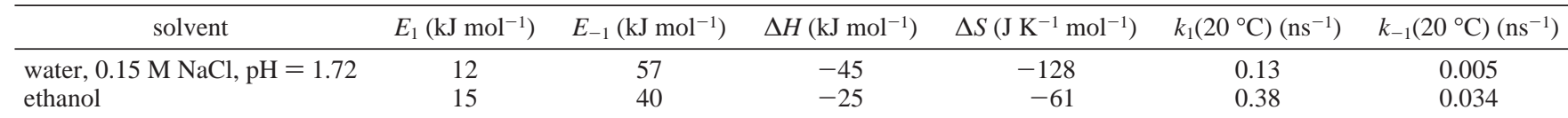


and that even for a tetramethylene chain the excimer intensity was already very small. This is in clear contrast with our system where a large excimer to monomer emission ratio is observed. In fact, a general rule for diaryl alkanes states that the maximum in excimer formation occurs for $n=3$ (Hirayama rule). ${ }^{29}$ This reflects the pronounced chain length dependence originated from conformational requirements needed to be attained so the alkyl chain can reach the specific sandwich-like structure, of the two naphthyl end groups, that ensures a sufficiently large intramolecular orbital overlap in the excimer. This chain length dependence leads, in the case of diaryl alkanes, to a minimum in excimer formation for $n=7$, a chain cyclization problem analogous to the well-known minimum in the yield for chemical ring closure reactions with 10-membered rings. ${ }^{30}$ For $n>12$, the dominant chain control for excimer formation is clearly reduced, ${ }^{31}$ and this is the case of our system $(n=15)$. Another important aspect is that the use of relatively long chains minimizes $^{32}$ the conformational effects which is opposite to the case of short linking chains where a more complex kinetic treatment is found..$^{33}$

It was also previously observed that an increase in the degree of protonation of the polyamine decreases the excimer binding energy, as a result of the increase of the electrostatic repulsion upon protonation. ${ }^{15}$ The electrostatic repulsion contributes largely to the changes in the excimer binding energy and the activation energy for excimer dissociation, having a strong effect on the slope of the Arrhenius plot for $k_{-1}$. This repulsion can be modulated both by the $\mathrm{pH}$ and the dielectric constant of the medium, thus affecting the sensitivity of the system toward temperature changes. This opens a field toward the development of tunable dual fluorescence temperature sensors. Intramolecular monomer-excimer based temperature sensors such as compound $\mathbf{L}$ have the advantage of being independent of the concentration of the probe. Temperature can be measured as a linear function of both steady state $\left(I_{\mathrm{E}} / I_{\mathrm{M}}\right)$ or time-resolved fluorescence $\left(1 / \tau_{1}\right)$ parameters in the temperature range $20{ }^{\circ} \mathrm{C}$ $<T<60^{\circ} \mathrm{C}$, in water. In the particular case of compound $\mathbf{L}$, the average percentage relative sensitivity is better for steady state $\left(4.5 \% /{ }^{\circ} \mathrm{C}\right)$ than for time-resolved fluorescence $\left(3.2 \% /{ }^{\circ} \mathrm{C}\right)$.

\section{Conclusions}

A chemosensor consisting of a tripodal polyamine receptor bearing naphthalene fluorophores at the terminals has been shown to exhibit an intense excimer emission, due to the increased probability of excimer formation, when compared with bis-fluorophoric systems. The kinetics of excimer formation was studied by time-correlated single photon counting in water and ethanol as a function of temperature. From the temperature dependence of rate constants, the activation energy $\left(E_{1}\right)$ and entropy change $(\Delta S)$ for excimer formation and dissociation $\left(E_{-1}\right)$ and the binding energy of the excimer $(\Delta H)$ were obtained.

One of the most interesting characteristics of this system is the dependence of the kinetic and thermodynamic parameters on the dielectric constant of the medium and on the degree of protonation of the chains. This result opens the possibility to use $\mathrm{pH}$ and solvent to modulate the temperature sensor ability of these systems.
Acknowledgment. Financial support from FCT project 32442/99 (Portugal), PRAXIS/QUI/10137/98, HPRN-CT-200000029 "Molecular Level Devices and Machines" (EC), and DGICYT project BQU2000-1424 (Spain) and the SpanishPortuguese Program of Acciones Integradas No. E-38/02 are gratefully acknowledged.

\section{References and Notes} 9898

(1) Chandrasekharan, N.; Kelly, L. A. J. Am. Chem. Soc. 2001, 123 ,

(2) Enseger, M.; Fabbrizzi, L.; Lichelli, M.; Sacchi, D. Chem. Commun. 1999, 1191

(3) Miguel, M. D. Adv. Colloid Interface Sci. 2001, 89, 1.

(4) Valeur, B. In Molecular Luminescence Spectroscopy. Methods and Applications; Schulman, S. G., Ed.; Wiley-Interscience: New York, 1993; Part 3.

(5) Castanheira, E. M. S.; Martinho, J. M. G.; Duracher, D.; Charreyre, M. T.; Elaissari, A.; Pichot, C. Langmuir 1999, 15, 6712.

(6) Stevens, B.; Ban, M. I. Trans. Faraday Soc. 1964, 60, 1515. 1970.

(7) Birks, J. B. Photophysics of Aromatic Molecules; Wiley: London,

(8) Albelda, M. T.; Bernardo, M. A.; Díaz, P.; García-España, E.; Seixas de Melo, J.; Pina, F.; Soriano, C.; Santiago, V. L. E. Chem. Commun. 2001, 1520 .

(9) Pina, F.; Bernardo, M. A.; García-España, E. Eur. J. Inorg. Chem. 2000, 2143.

(10) Bernardo, M. A.; Alves, S.; Pina, F.; Seixas de Melo, J.; Albelda, M. T.; García-España, E.; Llinares, J. M.; Soriano, C.; Luis, S. V. Supramol. Chem. 2001, 13, 435.

(11) Pina, F.; Lima, J. C.; Lodeiro, C.: Seixas de Melo, J.; Díaz, P. Albelda, M. T.; García-España, E. J. Phys. Chem. A 2002, 106, 8207.

(12) Gans, P.; Sabatini, A.; Vacca, A. Talanta 1996, 43, 1739.

(13) Seixas de Melo, J.; Fernandes, P. F. J. Mol. Struct. 2001, 565, 69.

(14) Striker, G.; Subramaniam, V.; Seidel, C. A. M.; Volkmer, A. J. Phys. Chem. B 1999, 103, 8612.

(15) Seixas de Melo, J.; Albelda, M. T.; Díaz, P.; García-España, E.; Lodeiro, C.; Alves, S.; Lima, J. C.; Pina, F.; Soriano, C. J. Chem. Soc., Perkin Trans. 2 2002, 991.

(16) Winnik, F. M. Chem. Rev. 1993, 93, 587.

(17) Bur, A. J.; Vangel, M. G.; Roth, S. Appl. Spectrosc. 2002, 56, 174 and references therein.

(18) de Silva, A. P.; Gunaratne, H. Q. N.; Jayasekera, K. R.; O'Callaghan, S.; Sandanayake, K. R. A. S. Chem. Lett. 1995, 123.

(19) Chapman, C. F.; Liu, Y.; Sonek, J. G.; Tromberg, B. J. Photochem. Photobiol. 1995, 62, 416 .

(20) Fister, J. C., III.; Rank, D.; Harris, J. M. Anal. Chem. 1995, 67, 4269.

(21) Engeser, M.; Fabbrizzi, L.; Licchelli, M.; Sacchi, D. Chem Commun. 1999, 1191

(22) Amao, Y.; Okura, I. Analysis 2000, 28, 847.

(23) Dressick, W. J.; Cline, J.; Demas, J. N.; DeGraff, B. A. J. Am. Chem. Soc. 1986, 108, 7567.

(24) Brewster, R. E.; Kidd, M. J.; Schuh, M. D. Chem. Commun. 2001, 1134

(25) Schrum, K. F.; Williams, A. M.; Haerther, S. A.; Ben-Amotz, D. Anal. Chem. 1994, 66, 1788.

(26) Robinson, G. W.; Thistlethwaite, P. J.; Lee, J. J. Phys. Chem. 1986, 90, 4224.

(27) Bell, R. P. The Proton in Chemistry; Methuen \& Co. Ltd.: London, 1959

(28) Chandross, E. A.; Dempster, C. J. J. Am. Chem. Soc. 1970, 92, 3586.

(29) Hirayama, F. J. Chem. Phys. 1965, 42, 3163.

(30) Winnik, M. A. Chem. Rev. 1981, 81, 491.

(31) Zachariasse, K. A.; Macanita, A. L.; Kuhnle, W. J. Phys. Chem. B 1999, 103, 9356.

(32) Van der Auweraer, M.; Gilbert, A.; De Schryver, F. C. Nouv. J. Chim. 1980, 4, 153.

(33) De Schryver, F. C.; Collart, P.; Vandendriessche, J.; Goedeweeck, R.; Swinnen, A. M.; Van der Auweraer, M. Acc. Chem. Res. 1987, 20, 159. 